\title{
The Cyanides of Gold
}

\section{THE HISTORY OF THEIR KEY ROLE IN ELECTROPLATING}

\section{Graham Williams}

One of the most widely known stories in the successful development of gold plating concerns the Birmingham surgeon John Wright, who in 1839 demonstrated for the first time that thick and adherent deposits could be obtained from a solution of gold cyanide in potassium cyanide (1). Like many other medical men of his time, Wright enjoyed experimenting with the new voltaic electricity. Among several early workers in this field was M. H. Jacobi of St. Petersburg, and the appearance of an account of his electrotyping process in The Athenaeum of May 8th, 1839 aroused considerable public interest. This probably stimulated. Wright, living and working in Birmingham where gilding and silvering were extensively practised, to attempt to devise electrogilding and silvering processes. After carrying out a number of experiments to no avail he decided to do no further work on the subject, left his small laboratory, and sat down in his library. Here he picked up the English version of 'Chemical Essays' by the famous Swedish chemist Carl Wilhelm Scheele, first published in 1783 and translated into English in 1786 by Thomas Beddoes, then just down from Oxford, from the original papers in the Transactions of the Academy of Sciences at Stockholm. There, in 'Dissertation on Prussian Blue Part II', he came across a passage which led him to the solution of his problem (2). This crucial passage is reproduced here from Beddoes' translation, and it is likely that Wright's attention was particularly drawn to it by a postscript to Beddoes' preface:
P.S. Having fortunately procured the second part of the paper on Prussian blue since this preface went to the press, I have subjoined it at the end of the present volume, that the reader might not be left in a disagreeable state of suspense by the half-finished discussion of so interesting a subject."

That this was in fact the crucial passage was confirmed many years later by the famous metallurgist Professor John Percy, who had been a physician at the Birmingham Medical School during the years 1841 to 1845 and who had been told the story by Wright himself (3), but it is worth noting that Scheele stated more explicitly some ten pages earlier:

'If a quantity of this liquor potassium cyanide solution be poured into a well saturated solution of gold, the gold precipitates in the form of a white powder; but if it be added in excess, the precipitate will be redissolved. This solution is colourless like water' (4).

Within a few weeks Wright had perfected both silver and gold electrolytes based upon potassium cyanide - a development which was to lay the foundations of commercial electroplating.

T. H. Rollason, a nephew of Mrs. Wright, wrote many years later:

'In 1839, as a schoolboy at King Edward's College, I was visiting Dr. Wright's house, 122 High St., Bordesley, and perfectly recollect when one morning at breakfast he showed to my aunt, Mrs. Wright, a metal plate he had just silvered and a brass metal chain he had gilt by the electro-process he had just invented. He was in high glee at his success."

Unfortunately John Wright, for some peculiar reason, kept his records in German shorthand, and these were burnt as waste paper after his death following a fall from his dog cart in 1844 .

The sequel to this discovery, as is also well known, was the agreement with the Elkington cousins and the incorporation of Wright's cyanide solutions in the Elkington patent that had been applied for in March of 1840 and which was granted in the following September (5). The Elkingtons retained a consulting chemist, John Thomas Cooper, to advise them during their negotiations with John Wright, and he is on record as commenting, in September 1840:

'The cyanides with anything that contains gold does the trick instanter'.

Now by 1840 a number of people were actively seeking practicable methods of electroplating with gold and silver, and it therefore seems relevant to ask whether it was necessary to reach back over fifty years to Scheele for the answer to the problem, and to enquire into the then state of 
knowledge of the relevant compounds that we now call complex cyanides.

Scheele's work on both the gold and silver compounds was reported by C. L. Berthollet in his 'Essai de Statique Chimique' published in 1803 and translated into English by B. Lambert in the following year. Berthollet described the complexes as 'triple prussiates', a term that had been used by Scheele (2). In 1806 Berthollet's great rival Joseph Louis Proust, then in Madrid, mentioned the ability of silver to form a triple prussiate but denied the formation of such a compound of gold:

'There are metals which are susceptible of forming simple and triple prussiates, such as copper, silver, manganese, cobalt, nickel, uranium, etc. There are some which give only the simple prussiate such as gold, mercury, etc. There are some which give triple only, such as iron, etc. Lastly others do not appear susceptible either of one or the other. But with the exception of prussian blue and prussiate of mercury, all the rest are little known, and merit examination' (6).

After Proust there is very little reference to the complex gold cyanide until Berzelius mentioned it in Swedish in 1822, in German in 1826 and in French in 1831 (7), crediting the discovery of both the gold and silver compounds to Franz von Ittner, professor of pharmacy in the University of Freiburg im Breisgau. Ittner had in fact published a small book, his doctoral thesis, back in 1809 , 'Beiträge zur Geschichte der Blausäure mit Versuchen über ihre Verbindungen und Wirkungen auf den Theorischen Organismus', but this seems to have received little attention, nor was it translated into English or any other language.

In the course of this work Ittner wrote:

\begin{abstract}
'Scheele states in his frequently quoted thesis that precipitates formed in the solutions of gold, silver and copper by potassium cyanide are dissolved again if further cyanide is added; that this solution is not decomposed by carbonic acid as is the case with potassium cyanide, i.e. a triple salt could have formed during the operation.

I thought it would be interesting to repeat and follow up Scheele's experiments to satisfy myself whether or not these compounds could be ranked with iron cyanide and what would be the properties of the metallic precipitates produced by their action.

I agitated gold cyanide together with potassium cyanide until no more of the former was dissolved. The solution was orange in colour. Its taste had changed from the alkaline bitterness of potassium cyanide to a metallic tartness which, however, was nothing like as unpleasant as silver potassium cyanide.

Gold potassium cyanide likewise crystallised out after evaporation. The resulting crystals were too small to determine their shape, but they appeared to be three-sided pointed pyramids. These were transparent and pale yellow in colour.'
\end{abstract}

The silver compound was mentioned by R. Porrett in 1814 (8). He suggested that the 'triple prussiate' of iron and potash was the salt of potash and an acid he named ferrureted chyazic acid, and that analogous compounds existed such as argenturetted chyazic acid and sulphuretted chyazic acid!
It is remarkable, that our colouring matter, after it has united with the alkali, or with the lime, forms a menftruum, capable not only of diffolving metallic calces, but alfo of conftituting a triple falt, which is not decompofed by the aerial acid, as happens with the lixivium fanguinis and the precipitating liquor, when expofed to the free accefs of air. Iron is not the only metal which has the property of fixing the colouring matter ( $\$ \mathrm{II}, \mathrm{c})$, the fame quality belongs likewife to gold, filver, copper, and probably to feveral other metallic calces; for if after thefe calces have been precipitated, a fufficient quantity of precipitating liquor be adicel, in order to rediffolve them, the folution remains clear in the open air, and in this ftate the aerial acid does not precipitate the metallic calx.

Fac-simile of one of the passages in the English translation by Thomas Beddoes (1786) of Carl Wilhelm Scheele's 'Dissertation on Prussian Blue' (1783) which led John Wright to try the complex cyanides as electrolytes for gold and silver plating. This passage refers to the solubility in hydrocyanic acid ('our colouring matter') of the cyanides ("calces") of gold, silver and copper to complex salts that are not decomposed, as is an aqueous solution of potassium cyanide ('lixivium sanguinis'), on exposure to the carbon dioxide of the air ('the aerial acid')

In $1815 \mathrm{~J}$. L. Gay-Lussac described in the Annales de Chime (9) how he had evaporated a solution of silver cyanide in potassium cyanide and obtained hexagonal plates soluble in water. GayLussac's paper appeared in English in 1816 (10). In 1834 Gay-Lussac's preparation of crystals of the silver compound was also mentioned by F. Rodgers and E. Rodgers (11) but they made no mention of the corresponding gold compound.

The text books of the early part of the nineteenth century gave more emphasis to potassium ferrocyanide because of its relationship to Prussian Blue and its use in qualitative analysis. A. F. de Fourcroy, for example, in his 'Système des Connaissances Chimiques', published in 1801 anci translated into English by William Nicholson in 1804, made general statements on the ability of potassium cyanide to form 'triple prussiates' with metal oxides but did not specifically refer to the oxides of gold or silver in this connection. This was also the case with the numerous editions of Thomas Thomson's 'System of Chemistry' which appeared between 1802 and 1810. Frederick Accum's 'System of Theoretical and Practical Chemistry', published in 1807 , made no mention 


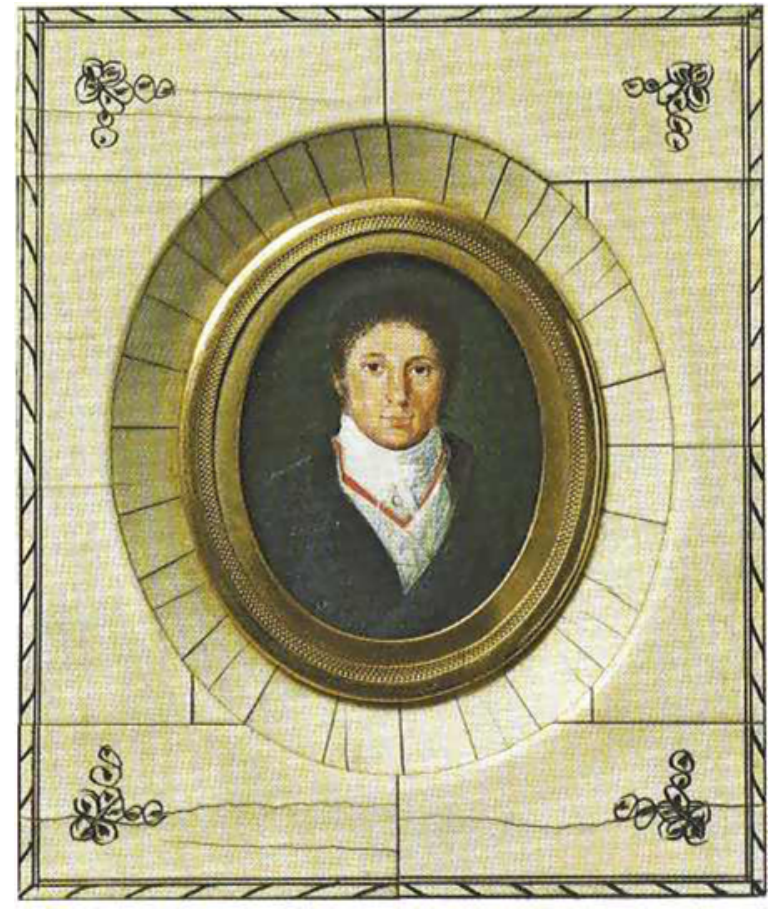

of the complex gold or silver cyanides, while William Henry in his 'Elements of Experimental Chemistry', 1810, merely stated briefly that:

'The prussiated alkalies decompose also all metallic solutions except those of gold, platinum, iridium, rhodium, osmium and antimony' (12).

In various editions of Louis Jacques Thenard's 'Traité de Chimie' between 1815 and 1834 the solubility of silver cýanide in excess alkali cyanide was mentioned but, perhaps after Proust, gold cyanide was described as being insoluble, a statement that was repeated in Henry's 1826 edition of his 'Elements of Experimental Chemistry'

In his 'Lärbok i Kemien' in 1822 and his 'Lehrbuch der Chemie', 1826, Berzelius referred to the complex gold and silver cyanides as 'double' instead of 'triple' salts, and they then came to be looked upon as analogous to double sulphides and halides. Berzelius also referred to the 'double cyanides of gold and silver' in his 'Traité de Chimie' in 1831. Edward Turner, in his 'Elements of Chemistry' published in 1833 mentioned the double cyanides of iron, zinc, cobalt, nickel and copper, but failed to include the gold and silver compounds. In the 1830's the only English text book to mention the double cyanide of silver and potassium was Thompson's 'System of Chemistry' of 1831, but no mention was made of the corresponding gold compound.

Ure's famous 'Dictionary of Chemistry', published in 1821 and re-issued in 1824 and 1835, described the preparation by Gay-Lussac in 1815 of the 'triple hydrocyanate of potash and silver'

\section{Carl Wilhelm Scheele 1742-1786}

Probably the greatest chemist of his period, Scheele was for many years an obscure apothecary in a small town in Sweden, harrassed by poverty. His remarkable discoveries included oxygen, chlorine, hydrofluoric acid, and a number of organic acids. He characterised the well known dyestuff Prussian Blue and in the course of this work isolated hydrocyanic acid and found that gold cyanide was soluble in potassium cyanide

This miniature is in the possession of the Swedish Society of Pharmacists in Stockholm, by whose kind permission it is reproduced here

but made no reference to the corresponding gold compounds, while nomention of either the silver or gold compounds occurred in the various encyclopaedias of the period that have been consulted.

It appears, then; that very little mention of the complex cyanide of gold, but rather more of the corresponding silver compound, was made in scientific journals, text books of chemistry or chemical works of reference. Such references as there were had no significance regarding John Wright's discovery, but once he had made it the analogy between double cyanides and other double salts was perceived and most substances subsequently proposed for electrogilding and silvering fell within this classification. The coherent deposits obtained using cyanide solutions were explained by the absence of corrosion of the metal to be plated. Two reasons were given. First, corrosion was reduced because the cyanide solutions were alkaline, as opposed to acid. Secondly, in these solutions the gold was in its lowest oxidation state in combination. Hence there was no possibility of it oxidising the other metal present.

The working arrangement between John Wright and the Elkingtons quickly developed into a successful commercial undertaking, but unfortunately Wright did not live to see his ideas come to full fruition as he died at the early age of 35 in 1844. In the meantime news of his discovery had spread rapidly to France, to Russia and to Germany, and from this last country there was one further interesting development. In 1841 Werner von Siemens, later to be the founder of the great electrical concern, but then a young artillery officer, was sentenced to be confined in the fortress of Magdeburg in Prussia for taking part in a duel. Deeply interested in both Jacobi's published work on copper electrodeposition and Daguerre's new process of photography in which sodium thiosulphate was employed to dissolve the gold and silver salts, he had suitable apparatus and chemicals smuggled into his cell. He immediately 
succeeded in gold plating a German silver spoon from a thiosulphate bath, using a Louis d'or as anode. He then sold his process to a Magdeburg jeweller for forty Louis d'or, which provided him with the means to make further experiments including the use of cyanides. Years later he wrote :

'When in the year $1842 \mathrm{I}$ applied for my first Prussian patent (13) no process of galvanic gilding or silvering was known in Germany. I had experimented with all the gold and silver salts known to me, and besides the hyposulphites had also found the cyanides suitable. The patent however was only granted to me for the former, as in the meantime Elkington's English patent for the employment of the cyanide salts had become known. Notwithstanding the beautiful gold and silver precipitates obtainable from hyposulphite salts, the cyanide salts have in the long run kept the field, their solutions being more constant' (14).

While this was going on, Siemens' brother-inlaw Carl Himly, later Professor of Chemistry at the University of Kiel but then a lecturer at Göttingen, had taken up the study of both the simple and the double cyanides of gold. In his paper (15) published in 1842 he acknowledged the existence of the Elkington patent and the superiority of the cyanide electrolytes and went on to report a number of careful analyses of these compounds.

The chemistry of the gold cyanides was finally put on a sound basis by two employees of the Elkingtons, Charles Glassford and James Napier, in a paper 'On the Cyanides of the Metals, and their Combinations with Cyanide of Potassium. Part I. Cyanide of Gold', read to the Chemical Society in 1844 (16). Both were at that time engaged as chemists and electrometallurgists at the London works opened by George Elkington in Moorgate Street, and both were later to follow distinguished careers in the chemical industry, while Napier also achieved a reputation as an archaeologist; he was also the author of 'A Manual on Electrometallurgy', published in 1857. The introductory paragraph of their paper admirably sums up the situation that the present writer has attempted to record:

'The various compounds which cyanogen forms with the metals constitute one of the most interesting class of bodies which the science of chemistry can produce, and the rapid progress of electrometallurgy, with the almost universal use of these cyanides in the practice of this art, adds a double interest to the study of these compounds with the alkaline cyanides. Indeed, we might have expected that long before this some definite information would have been published upon the nature, constitution and easy preparation of these salts, as yet however, so far as we are aware, nothing complete has appeared. With a view to remedy this, and to facilitate a full investigation of the subject, we have drawn up the following observations, the result of extensive practical operations in the art of electrometallurgy, which we beg to present to the Chemical Society, in the hope that our results, in connexion with those of others who may be labouring in the same field, may lead to a more precise knowledge of their character and constitution.

\section{References}

1 L. B. Hunt, Gold Bull., 1973, 6, (1), 16-27

2 C. W. Scheele, 'Chemical Essays', translation by T. Beddoes, London, 1786, 405

3 J. Percy, 'Metallurgy: Silver and Gold', Part I, London, 1880,115

4 C. W. Scheele, op. cit., 395

5 British Patent 8447,1840

6 J. L. Proust, Ann. Chim., 1806, 60, 249

7 J. J. Berzelius, 'Lärbok i Kemien', 2nd ed., Vol. 2, Stockholm, 1822, 261; 'Lehrbuch der Chemie', Vol. 2, Dresden, 1826 , 936 \& 960; 'Traité de Chimie', Vol. 4, Paris, 1831, 403 \& 471

8 R. Porrett, Phil. Trans., 1814, (2), 532

9 J. L. Gay-Lussac, Ann. Chim., 1815, 95, 228

10 Ann. Philos., 1816, 8, 108-115

11 F. Rodgers and E. Rodgers, Phil. Mag., 1834, 4, 96

12 W. Henry, 'Elements of Experimental Chemistry', Vol. 2, London, 1810,330

13 The corresponding British Patent is No. 9741 of 1843 filed in the name of Siemens' patent agent, Moses Poole

14 'Werner von Siemens, Inventor and Entrepreneur', 2nd edition, London, 1966, 86

15 C. Himly, Liebigs Ann., 1842, 42, 151-163, 337-345

16 C. F. O. Glassford and J. Napier, Phil. Mag., 1844, 25, 56-71

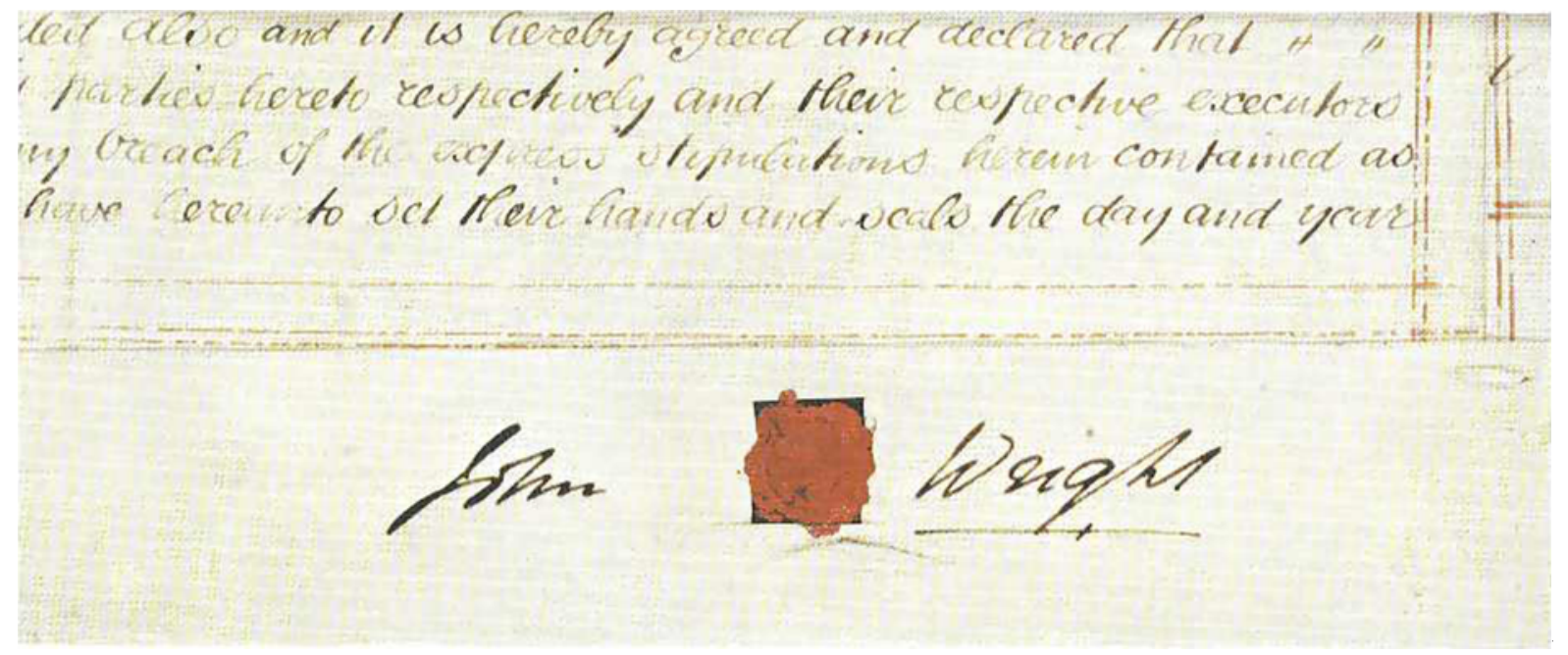

Dr. John Wright's signature to the memorandum of agreement with the Elkington cousins, George Richards and Henry. The document is dated September Ist, 1840 